\title{
Clause-Level Tense, Mood, Voice and Modality Tagging for German
}

\author{
Tillmann Dönicke \\ University of Göttingen \\ Göttingen Centre for Digital Humanities \\ Papendiek 16, 37073 Göttingen, Germany \\ tillmann.doenicke@uni-goettingen.de
}

\begin{abstract}
We present a language-independent clausizer (clause splitter) based on Universal Dependencies (Nivre et al., 2016), and a clause-level tagger for grammatical tense, mood, voice and modality in German. The paper recapitulates verbal inflection in German-always juxtaposed with its close relative English - and transforms the linguistic theory into a rule-based algorithm. We achieve state-of-the-art accuracies of $92.6 \%$ for tense, $79.0 \%$ for mood, $93.8 \%$ for voice and $79.8 \%$ for modality in the literary domain. Our implementation is available at https://gitlab.gwdg. de/tillmann.doenicke/tense-tagger.
\end{abstract}

\section{Introduction}

A clause is a syntactic unit within a sentence that contains a verb and all of its arguments (subject, object etc.) and adjuncts (adverbials of time, location etc.), i.e., clauses describe events (or states) and therefore are the core elements of discourse. Several important properties of an event are expressed by inflectional features of the verb alone: Tense and aspect express the relation between event time, speech time and reference time (Reichenbach, 1947; Boogaart and Janssen, 2007), mood expresses the reality status of an event (Elliott, 2000), and voice expresses a mapping between the syntactic arguments of a verb and semantic roles (agent, patient etc.). Modal verbs further mark the modality of an event, such as deonticity and epistemicity (Leiss, 2008). Hence, extracting these features from a clause is a crucial task for discourse analysis. Following previous work (Bögel et al., 2014; Ramm et al., 2017), we address this task with a rule-based approach.

We use parse trees in the Universal Dependencies (UD; Nivre et al. (2016)) format to split sentences into clauses, which makes our clause-splitting method applicable to all languages with a UD treebank. Nevertheless, the morphosyntactic systems for tense, aspect, mood, voice and modality vary greatly between languages (cf. Aronson (1995), Zeitoun et al. (1996), Lin (2005), Keenan and Dryer (2007), Singh et al. (2007) and many others) and do not allow a crosslinguistic approach. We focus on German which shows strong parallels to English.

This paper presents an approach towards tagging morphosyntactic/grammatical features which do not always correspond to semantic features. This is best observable for tense; all of the following examples feature present tense but describe events in the present, past or future:

(1) a. John sees Mary.

b. $44 \mathrm{BC}$, Caesar is stabbed by a group of senators. (historical present, Wolfson (1978))

c. Tomorrow, we go to the cinema. (future present)

Tagging and normalising temporal expressions such as $44 \mathrm{BC}$ and tomorrow is a separate research task (cf. Strötgen and Gertz (2010), Pustejovsky and Verhagen (2009) and subsequent SemEval tasks) which is not addressed in this paper. In the long run, both temporal expressions and grammatical tense together are helpful for inferring semantic tense.

The difference between syntax and semantics also affects the other features under consideration. The presence of a modal verb, for example, can cause multiple semantic interpretations: he must work is ambiguous between he is required to work (deontic interpretation) and he is very likely to work [according to what the speaker knows] (epistemic interpretation) (Viebahn and Vetter, 2016; Tarvainen, 1976). 


\begin{tabular}{lll}
\hline Tense + Aspect & Alternate names & Example (indicative, active) \\
\hline present imperfect & present & sieht 'sees' \\
present perfect & perfect & gesehen hat 'has seen' \\
past imperfect & preterite, imperfect & sah 'saw' \\
past perfect & pluperfect & gesehen hatte 'had seen' \\
future imperfect & future, future I & sehen wird 'will see' \\
future perfect & future II & gesehen haben wird 'will have seen' \\
\hline
\end{tabular}

Table 1: Tense-aspect combinations in German.

Grammatical tense also plays an important role in the analysis of narrative texts which are usually written in the simple past. If the tense changes locally, this marks a potential passage of interest. For example, if the tense changes to the simple present, it could be a passage with gnomic reading (i.e. a passage expressing a general truth) as in (2):

(2) John tried to catch a rabbit. Rabbits are fast, but finally he got it.

This paper is structured as follows: section 2 gives an overview of the inflection of verbs in German; section 3 summarises the previous approaches to tagging tense, mood and voice in German; section 4 contains our algorithms and implementation details; sections 5 and 6 contain the evaluation and discussion of our tool, including comparisons with the previous works; sections 7 and 8 conclude with an outlook on future work and a summary.

\section{Inflection and Government in German Clauses}

German has three tenses: present, past, future, and two aspects: imperfect (= simple) and perfect, and therefore six tense-aspect combinations (Table 1). The composition of verb forms is very similar to their English counterparts; a main verb is extended by auxiliary verb forms of haben 'have', sein 'be' and werden 'will/become/get'. For example, the past perfect form of sehen 'see' is (er) hatte gesehen '(he) had seen'. Since tense and aspect are inseparable, they are sometimes simply referred to as "tense".

German further distinguishes four moods: indicative, present subjunctive (subjunctive I), past subjunctive (subjunctive II) and imperative, as well as three voices: active, dynamic passive and static passive ${ }^{1}$. All of these are expressed by combinations of the three auxiliary verbs mentioned above.

\subsection{Word Order}

The basic German word order is S-O-V. All verbs are positioned at the end of a clause; starting with the syntactically lowest verb and ending with the syntactically highest verb. However, this ordering is only maintained in subordinate clauses; in main clauses, the finite verb (which is always the syntactically highest verb) moves to verb-second position ${ }^{2}$ :

\footnotetext{
${ }^{1}$ German makes a clear distinction between the dynamic passive using the auxiliary verb werden 'get' (3a) and the static passive using the auxiliary verb sein 'be' (3b). In English, on the other side, passives with be are ambiguous between a dynamic and a static reading:

(3) a. i. Er wird gefüttert [und verschlingt seinen Fraß].

ii. He is/gets fed [and is devouring his food].

b. i. Er ist gefüttert [und schläft jetzt].

ii. He is/*gets fed [and is now sleeping].

${ }^{2}$ In polar questions, the finite verb moves to sentence-initial position; in subordinate clauses, the finite verb may move to the so-called Oberfeld (cf. e.g. Hinrichs (2016)). For this paper, it is enough to say that the finite verb can move to a position preceding the non-finite verbs.
} 
(4) a. i. (dass) er sie gesehen hatte.

ii. (that) he had seen her.

b. i. Er hatte ${ }_{1}$ sie gesehen $t_{1}$.

ii. He had seen her.

English, as an S-V-O language, employs the exact opposite order of verbs. In other words, the direction of verbal government is right-to-left in German, and left-to-right in English:

(5) i. (dass) er sie gesehen haben wird.

ii. (that) he will have seen her.

The strict ordering makes it possible to derive the syntactic hierarchy of the verbs in a clause without applying a syntactic parser.

\subsection{Morphological vs. Clausal Features}

As we have seen in (4) and (5), a verb form can consist of several verbs. Each verb has its own morphological features. The features of a composite verb form (= the clausal features) result from the morphological features of the individual verbs. We use feature structures, i.e. sets of FEATURE-value pairs, (see Jurafsky and Martin (2009) for an introduction), to represent morphological and clausal features. Clausal features cannot be derived by unification of the involved morphological features though; this is why we denote the compositional process with a function $R$ which maps a set of morphological features to the features of the clause. For (4) we get:

$$
R\left\{\left\{\left[\begin{array}{cc}
\text { LEMMA } & \text { sehen } \\
\text { TYPE } & \text { main } \\
\text { FORM } & \text { participle } \\
\text { ASPECT } & \text { perfect } \\
\text { VOICE } & \text { passive }
\end{array}\right],\left[\begin{array}{cc}
\text { LEMMA } & \text { haben } \\
\text { TYPE } & \text { auxiliary } \\
\text { FORM } & \text { finite } \\
\text { TENSE } & \text { past } \\
\text { MOOD } & \text { indicative } \\
\text { VOICE } & \text { active }
\end{array}\right]\right\}\right)=\left[\begin{array}{cc}
\text { FORM } & \text { finite } \\
\text { TENSE } & \text { past } \\
\text { ASPECT } & \text { perfect } \\
\text { MOOD } & \text { indicative } \\
\text { VOICE } & \text { active }
\end{array}\right]
$$

\subsection{Modal Verbs}

Modal verbs are not part of a composite verb form but possibly take over inflectional features. (6a) and (6b) are identical in terms of tense, mood and voice but the modal verb muss 'must' in (6b) shows the inflectional features of the auxiliary verb hat 'has' in (6a).

(6) a. i. (dass) er sie gesehen $n_{[\text {FORM }}$ participle $]$ hat $\left[\begin{array}{cc}\text { FORM } & \text { finite } \\ \text { TENSE } & \text { present }\end{array}\right]$.

ii. (that) he has $\left[\begin{array}{cc}\text { FORM } & \text { finite } \\ \text { TENSE } & \text { present }\end{array}\right]$ seen $[$ FORM participle $]$ her.

b. i. (dass) er sie gesehen $n_{[\text {FORM participle }]}$ haben $_{[\text {FORM infinitive }]}$ muss $\left[\begin{array}{cc}\text { FORM } & \text { finite } \\ \text { TENSE present }\end{array}\right]$.

ii. (that) he must $\left[\begin{array}{cc}\text { FORM } & \text { finite } \\ \text { TENSE } & \text { present }\end{array}\right]$ have [FORM infinitive $] \operatorname{seen}_{[\text {FORM participle }]}$ her.

To obtain the basic verb form without (interfering) modal verbs, one has to shift their features to the next verb in the direction of verbal government. ${ }^{3}$

\footnotetext{
${ }^{3}$ In English, the shifting of inflectional features is also observable in negation or emphasis with the auxiliary verb $d o$ :

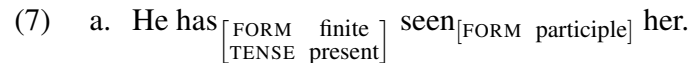

b. He does $\left[\begin{array}{cc}\text { FORM } & \text { finite } \\ \text { TENSE } & \text { present }\end{array}\right]$ (not) have ${ }_{[\text {FORM infinitive }]} \operatorname{seen}_{[\text {FORM participle }]}$ her.
} 


\subsection{Substitute Infinitives}

In German, modal verbs and some other verbs can exhibit a substitute infinitive (infinitivus pro participio), i.e. use the infinitive instead of the perfect participle. Müssen 'have to' in (8a) and hören 'hear' in (8b) (Bausewein, 1991) are substitute infinitives:

(8) a. i. (dass) er sie sehen müssen/*gemusst hat.

ii. (that) he has had to see her.

b. i. (dass) er sie singen hören/gehört hat.

ii. (that) he has heard her sing.

If substitute infinitives are governed by an auxiliary verb, this is always a form of haben 'have'.

\section{Previous Approaches and Corpora for German}

\subsection{Bögel et al. (2014)}

As part of the heureCLÉA project ${ }^{4}$, Bögel et al. (2014) developed a clause-level tagger for five tenseaspect combinations (future imperfect and future perfect are combined into one tag). Their pipeline is implemented in the UIMA framework ${ }^{5}$ and makes use of several external resources, such as the TreeTagger (Schmid, 1995) for part-of-speech tagging, the Stanford Parser for constituent parsing and Morphisto (Zielinski et al., 2009) as a morphological analyzer. Clauses ("sub-sentences" in Bögel et al. (2014)) are defined as constituents with an own $\mathrm{S}$ root. The final tense is predicted using a small set of rules, e.g.

$$
R\left(\left\{\left[\begin{array}{cc}
\text { TYPE } & \text { main } \\
\text { FORM } & \text { participle }
\end{array}\right],\left[\begin{array}{cc}
\text { TYPE } & \text { auxiliary } \\
\text { TENSE } & \text { present }
\end{array}\right]\right\}\right)=\left[\begin{array}{cc}
\text { TENSE } & \text { present } \\
\text { ASPECT } & \text { perfect }
\end{array}\right] \text {, }
$$

and a heuristic for discontinuities, which copies the tense for a clause from its neighbouring clauses if $R$ does not provide an analysis.

The evaluation corpus consists of twenty narrative texts, and the first $20 \%$ of each text (nearly $12 \mathrm{k}$ tokens in total) are annotated with tense. In the evaluation, they measured (i) all correctly tagged tokens (all tokens in a clause are assigned the same tense as the main verb), as well as (ii) only the correctly tagged main verbs. The reported accuracies are $94.8 \%$ and $93.3 \%$, respectively. Most of the tagging errors are caused by incorrect parser outputs (and thus incorrect clause splitting) or incorrect annotations.

The tense tagger was provided through the annotation tool CATMA ${ }^{6}$, version 5. Unfortunately, it was not transferred when moving to CATMA 6 (current version) and the account creation for CATMA 5 has been deactivated, which makes the tense tagger inaccessible. The corpus is still available at https: //github.com/heureclea.

\subsection{Ramm et al. (2017)}

The tmv-annotator by Ramm et al. (2017) is a Python tool for tagging preprocessed German, English or French texts with tense mood and voice. For German, the tagsets include all six tenses, three moods (imperative is missing) and two voices (no distinction between static and dynamic passive). To use the tool (available at https://github.com/aniramm/tmv-annotator), the texts have to be preprocessed with MATE tools ${ }^{7}$ - or another tool providing the same output—which is implemented in Java and includes tokenisation, part-of-speech tagging, lemmatisation, morphological analysis and depedendcy parsing (but no sentence splitting although the text has to be split into sentences before applying the tokeniser). Unlike the Stanford Parser which provides constituent parses, the MATE parser provides dependency parses in the German TIGER/CoNLL format (cf. Buchholz and Marsi (2006), Hajič et al. (2009)). The composite verb form of a clause ("verb cluster" in Ramm et al. (2017)) is extracted by first selecting the main verb and then collecting the dependent auxiliary verbs. The final analysis is predicted with a

\footnotetext{
${ }^{4}$ http://heureclea.de/

5 http://uima.apache.org/

${ }^{6}$ http: //www. catma.de/

${ }^{7}$ https://code.google.com/archive/p/mate-tools/
} 


Tokenizer $\rightarrow$ Lemmatizer $\rightarrow$ Tagger, Sentencizer, Parser $\rightarrow$ Clausizer $\rightarrow$ Analyzer $\rightarrow$ TMV Tagger

Figure 1: Our processing pipeline: from raw text to clause-level tagging.

rule-set similarly as in Bögel et al. (2014). The output of the tool is a table format providing all main verbs and tense/mood/voice tags as well as the clauses which contain the verbs.

The tool was evaluated on 157 randomly selected clauses from the Europarl corpus (Koehn, 2005) which had been annotated with the respective features. The reported accuracies are $80.8 \%$ for tense, $84.0 \%$ for mood and $81.5 \%$ for voice. Unfortunately, the evaluation corpus is not available anymore.

\section{Method/Implementation}

We implemented the entire pipeline in $\mathrm{spaCy}^{8}$, an open-source software library for crosslinguistic natural language processing in Python. The pipeline is shown in Figure 1; its individual components are described below.

\subsection{Preprocessing}

We used the default tokenizer, lemmatizer, part-of-speech tagger and sentencizer (sentence splitter) from the German spaCy model. ${ }^{9}$

\subsection{Universal Dependency Parsing}

Universal Dependencies (UD; Nivre et al. (2016) $)^{10}$ are a crosslinguistic annotation format and also a collection of treebanks from a wide range of languages annotated in that format. An advantage of the universal annotation format, with respect to our need for clause splitting, is that clauses can easily be identified through certain dependency relations (e.g. nsubj marks a nominal subject whereas csubj marks a clausal subject). This is not the case with, for example, the TIGER annotation scheme for German (here sb marks both non-clausal and clausal subjects). We therefore decided to parse our texts with UD relations.

Unfortunately, German and English are the only languages for which the default spaCy parser does not use UD relations. Therefore-and because there is currently no German UD model for spaCy available-, we trained a new parser on the current version of the UD treebanks (Zeman et al., 2020). In contrast to e.g. the Stanford parser which was solely trained on newspaper texts, the German UD treebanks also contain texts from different domains, including a small proportion of texts from literary history (LIT treebank). We held out the test sets of GSD and HDT (9.3\% of the sentences) for testing and achieved a labelled attachment score (Zeman et al., 2017) of $85 \%$. We provide our spaCy model along with the rest of our code.

\subsection{Crosslinguistic Clause Splitting}

As mentioned above, certain UD relations can be used to split a sentence into clauses. To be more precise, if one of the following relations is encountered in a sentence, the tokens of the corresponding subtree, ignoring punctuation, form a clause: root (matrix sentence), acl (adjectival clause), advcl (adverbial clause), ccomp (clausal complement), csubj (clausal subject), discourse (interjections etc.), parataxis, vocative, list. The relations xcomp (open clausal complement) and conj (conjunct) sometimes but not always mark clauses. We split at these relations if certain conditions are met: at an xcomp if the subtree constists of at least a verb and one additional word which is not a verbal particle (i.e. if the subtree forms an extended infinitive clause); at a conj if the label of its head is one of the clause labels listed above (i.e. if the subtree is conjuncted on clause-level). These conditions are hyperparameters in our implementation and can be easily changed if one prefers another handling of open clausal complements or conjuncts.

\footnotetext{
${ }^{8}$ https://spacy.io/

${ }^{9}$ The pre-trained German model is available at https://spacy.io/models/de\#de_core_news_lg.

${ }^{10}$ https://universaldependencies.org/
} 
(i)

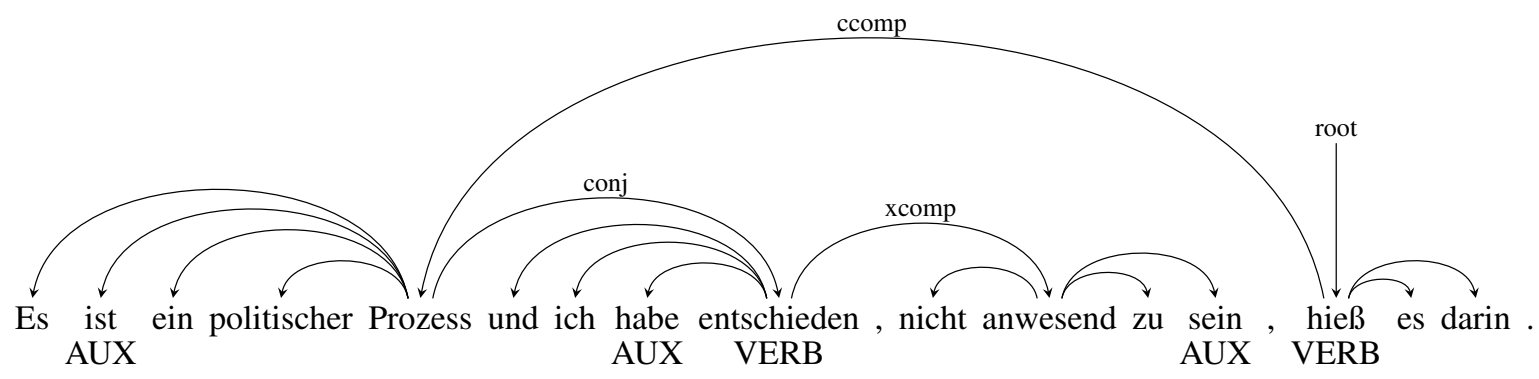

(ii)

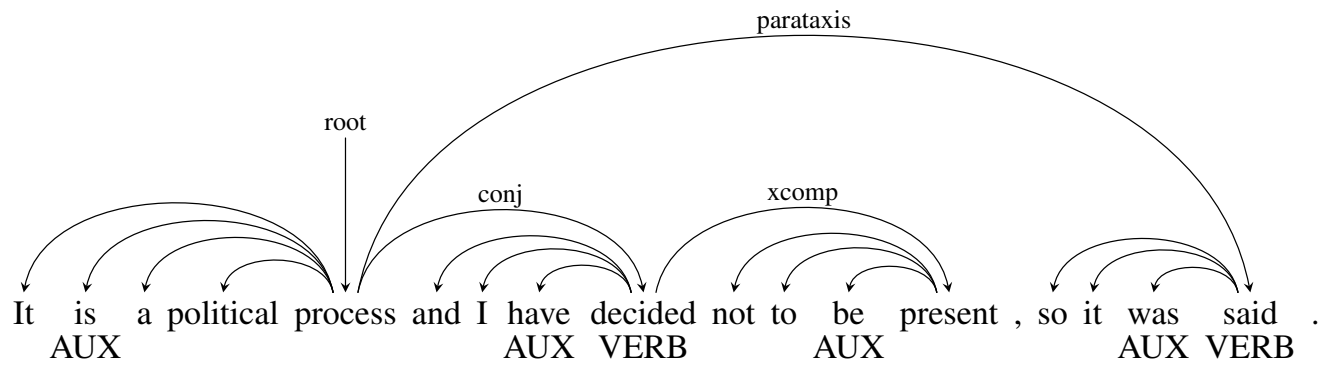

(iii)

\begin{tabular}{ll}
\hline Relation & Clause \\
\hline ccomp & Es ist ein politischer Prozess \\
conj & und ich habe entschieden \\
xcomp & nicht anwesend zu sein \\
root & $\underline{\text { hieß } \text { es darin }}$
\end{tabular}

(iv)

\begin{tabular}{ll}
\hline Relation & Clause \\
\hline root & It $\underline{\text { is a political process }}$ \\
conj & and I have $\underline{\text { decided }}$ \\
xcomp & not to $\underline{\text { be present }}$ \\
parataxis & so it $\underline{\text { was }} \underline{\text { said }}$ \\
\hline
\end{tabular}

Figure 2: Dependency trees for a sentence in the (i) German and (ii) English PUD treebanks (ID: n02030005). Relations are only labelled if marking a clause. Tables (iii) and (iv) show the extracted clauses; verbs are underlined.

Our clausizer is applicable to all texts with UD parse trees, either after being parsed accordingly (e.g. with spaCy) or after being manually annotated (e.g. within the UD treebanks project). Figure 2 shows a sentence from the German and English PUD treebanks. Each sentence contains four clauses. We implemented the clausizer to recursively detect nested clauses, e.g. two clauses are detected in (9): Der Mann lacht 'The man laughs' and der die Kuh sah 'who saw the cow'.

(9) i. Der Mann, der die Kuh sah, lacht.

ii. The man who saw the cow laughs.

\subsection{Morphological Analysis}

SpaCy already assigns some morphological features to words, e.g. the form of a verb, i.e. whether it is finite, an infinitive or a participle. In addition, we use DEMorphy (Altinok, 2018) ${ }^{11}$, a morphological analyzer for German. Since DEMorphy outputs all analyses for a word-independent from its contextwe filter out unlikely analyses due to case-number-gender congruence. To be more precise, the words within a noun phrase should be congruent in case, number and gender, and a finite verb should be congruent with its subject in number and person.

\subsection{TMV Tagging}

The algorithm for our tense-mood-voice (TMV) tagger is sketched in Algorithm 1. In the following, numbers in parentheses refer to the corresponding lines in the pseudocode.

Given a clause $C$, the non-finite verbs, i.e. infinitives and participles, are stored in a list $V$ (1. 1). In contrast to the procedure of Ramm et al. (2017), this step does not rely on the output of a parser. If the

\footnotetext{
${ }^{11}$ https://github.com/DuyguA/DEMorphy
} 


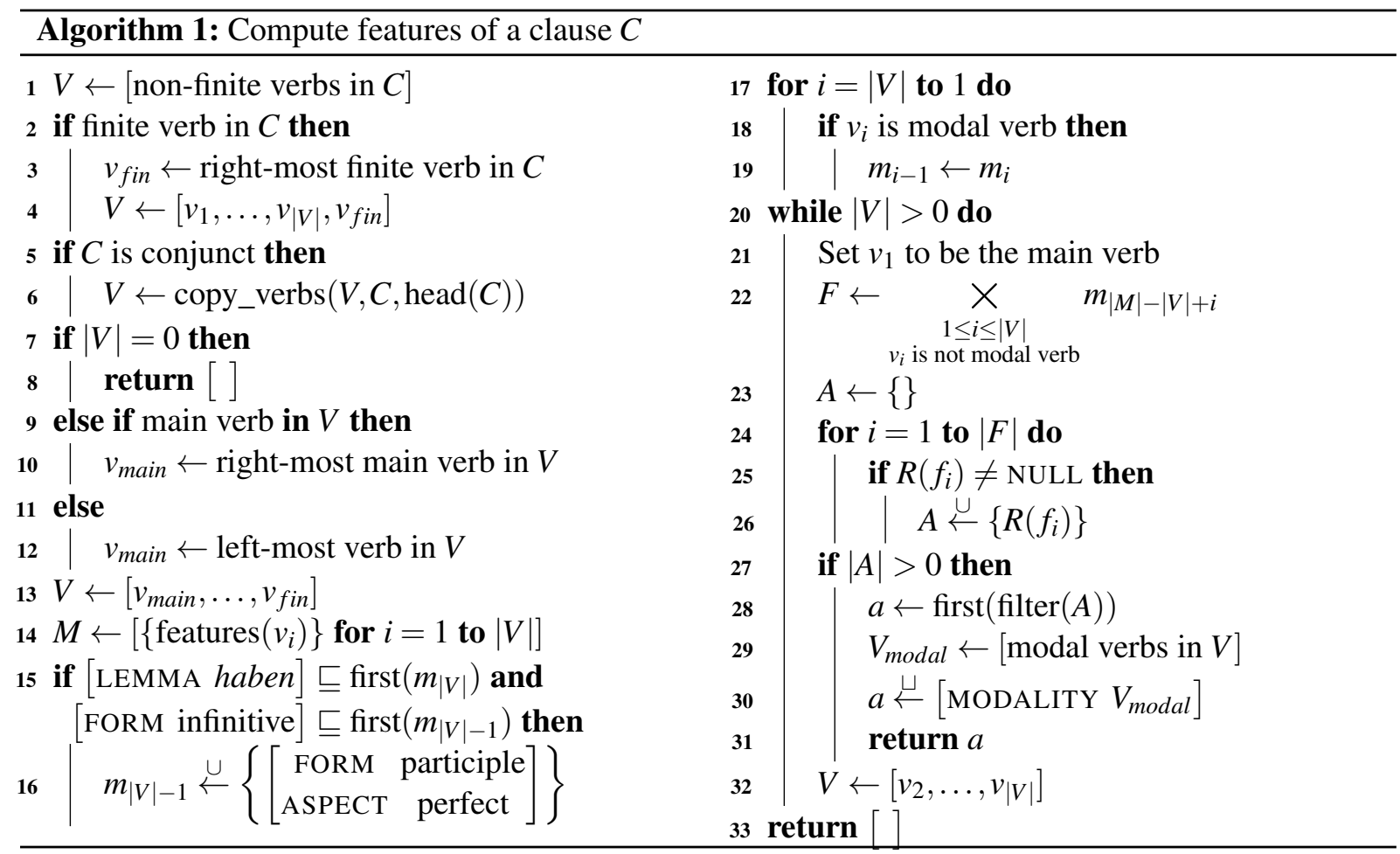

For a set $S=\left\{s_{1}, \ldots, s_{|S|}\right\}$, first $(S)$ is identical to $s_{1}$.

$\longleftarrow$ and $\longleftarrow$ are augmented assignment operators for union and unification, respectively.

clause contains a finite verb, then it is appended to $V$ (1l. 2-4). In that way, the verbs are sorted in basic word order, i.e. as if the clause was a subordinate clause.

If $C$ is a conjunct, the potentially missing verbs are copied from the head clause (11. 5-6). For example, (10) contains the clauses er sie gesehen hatte 'he had seen her' and und gerufen 'and called'; hatte 'had' has to be copied from the first to the second clause to complete the composite verb form gerufen hatte 'had called'.

(10) i. (dass) er sie gesehen und gerufen hatte.

ii. (that) he had seen and called her.

The next step is to select the clause's main verb. If there is at least one genuine main verb in $V$, the right-most (= syntactically highest) one is chosen (11. 9-10). In (11a), this is gelernt 'learned'. (11b) and (11c) illustrate that auxiliary verbs and modal verbs can function as main verb as well. If there is no genuine main verb in the clause, the left-most (= syntactically lowest) verb is chosen (11. 11-12). In (11b), this is gewesen 'been'; in (11c), this is kann 'can'. Note that speak is the main verb of the English translation since can cannot be used alone here; German is much freer in using modal verbs as main verbs.

(11) a. i. (dass) er sprechen gelernt hatte.

ii. (that) he had learned to speak.

b. i. (dass) er dort gewesen war.

ii. (that) he had been there.

c. i. (dass) er Englisch kann.

ii. (that) he can [speak] English.

Only the verbs from the main verb to the finite verb are interesting for TMV tagging, because the main verb is the syntactically lowest verb of a composite verb form; all other verbs which precede the main verb are removed from $V$ (1.13). $M$ contains the feature structures for every word, i.e. $m_{i}(1 \leq i \leq|V|)$ 
is a set of possible morphological analyses for $v_{i}$ (1. 14). If the second verb from the right $v_{|V|-1}$ is a potential substitute infinitive, the feature structure of a perfect participle is added to $m_{|V|-1}$ (ll. 15-16). Having all verbs of interest together, the features of modal verbs are shifted to their predecessors as described in section 2.3 (11. 17-19).

The Cartesian product of $m_{1}, \ldots, m_{|V|}$ (now ignoring modal verbs) yields all possible combinations of morphological analyses of the involved verbs and is stored in $F(1.22)$. Every combination $f_{i} \in F$ is then tried to be mapped to the clausal features $R\left(f_{i}\right)$. Instead of using hand-crafted rules like previous work, we created a table of all possible verb forms for the look-up (a table with all verb forms can be found in the appendix). If $f_{i}$ is in the table, then $R\left(f_{i}\right)$ is saved in the final set of analyses $A$ (11. 23-26).

If no analysis is found, the first verb in $V$ is removed (1.32) and the last paragraph is repeated (11. 2021). This counteracts tagging and parsing errors and makes it possible to also tag rarely used verb combinations such as sequences of auxiliaries as in (12a) or double perfect constructions (Ammann, 2007) as in (12b).

(12) a. i. (dass) er dort gewesen gewesen ist.

ii. (that) he has been been there.

b. i. (dass) er sie gesehen gehabt hat.

ii. (that) he has had seen her.

As soon as one or more analyses are found, one of them is selected and returned (11. 27-31). In German, most verbs express the perfect aspect with the auxiliary verb haben 'have' (e.g. hat gesehen 'has seen') but some use sein 'be' (e.g. ist gegangen 'is gone') and others can use either depending on the context or regional varieties (whereas in English it is almost always have). Since forms of sein can not only mark perfect aspect but also static passive, this causes ambiguous verb forms. To resolve these ambiguities, we filter the analyses with respect to the main verb's possible perfect auxiliaries (this is also done by Ramm et al. (2017)). We extracted the possible perfect auxiliaries for every German verb in the German Wiktionary ${ }^{12}$.

Before the final analysis is returned, its modality feature is set to the list of modal verbs in the current $V$ (11. 29-30) (syntactically lower modal verbs are not returned).

\section{Evaluation}

We compared the performances of our tagger and the tagger from Ramm et al. (2017) on the texts in the heureCLÉA corpus as well as on a text annotated by ourselves.

\subsection{Annotation}

We annotated the German translation of the preface of Don Quijote by Miguel de Cervantes Saavedra ${ }^{13}$ (3,200 tokens) which contains a lot of complex (multi-clause) sentences and examples for all six tenses, four moods, three voices and the modal verbs können 'can', mögen 'may', müssen 'must', sollen 'shall' and wollen 'want'. Two annotators annotated the text with tense. After calculating the inter-annotator agreement ( $\kappa=96 \%$, Fleiss et al. (2003)), we combined the two annotations into a gold annotation and extended it with finiteness, mood, voice and the modal verbs involved in a verb form.

We used the official German Duden grammar (Dudenredaktion, 2009, pp. $476 \mathrm{ff}$.) as reference guide for our annotation of tense, mood and voice. We also annotated non-finite clauses (with infinitive or participle forms) with tense and voice ${ }^{14}$ —non-finite forms do not feature mood—, whereas Ramm et al. (2017) only consider finite verb forms and in heureCLÉA non-finite clauses are either not annotated or receive the tense of the corresponding matrix clause.

\footnotetext{
${ }^{12}$ https://dumps.wikimedia.org/dewiktionary/

${ }^{13}$ The text is available at https://www.projekt-gutenberg.org/cervante/quijote1/quijote1.html.

${ }^{14}$ It is debatable whether infinitives and participles feature tense or only aspect. This is, however, only a matter of definition. Since we only tag tense-aspect combinations, we use the present imperfect or present perfect for all non-finite verb forms.
} 


\begin{tabular}{lcccc}
\hline & \multicolumn{2}{c}{ heureCLÉA } & \multicolumn{2}{c}{ Don Quijote } \\
& Tokens & Verbs & Tokens & Verbs \\
\hline Fleiss' $\kappa$ & $(89.7)$ & $(84.0)$ & 96.3 & 96.0 \\
Bögel et al. (2014) & $(93.3)$ & $(94.8)$ & - & - \\
Ramm et al. (2017) & 74.9 & 81.9 & 55.8 & 63.7 \\
this work & 88.8 & 90.8 & 87.2 & 92.6 \\
\hline
\end{tabular}

Table 2: Inter-annotator agreements and tense tagging accuracies for the heureCLÉA corpus and/or our test text. Numbers in brackets are copied from Bögel et al. (2014). Accuracies are shown for all tokens or only main verbs.

\begin{tabular}{lccccc}
\hline & Fin. & Tense & Mood & Voice & Mod. \\
\hline Ramm et al. (2017) & 82.7 & 71.5 & 75.7 & 82.5 & - \\
this work & 88.1 & 92.9 & 82.2 & 93.5 & 79.8 \\
& & 92.6 & 79.0 & 93.8 & 79.8 \\
\hline
\end{tabular}

Table 3: Comparison of two taggers for tense, mood, voice and modality on our test text. Accuracies are calculated for main verbs in finite clauses. The first column shows the accuracy distinguishing main verbs in finite clauses from main verbs in non-finite clauses.

\subsection{Tense Evaluation}

The first evaluation concentrates on tense tagging. Following Bögel et al. (2014), we provide the accuracy for correctly tagged tokens (where each token is assigned the tense of the clause) as well as the accuracy for the correctly tagged main verbs. Table 2 shows the accuracies for testing on the heureCLÉA corpus and our gold annotation of Don Quijote.

For heureCLÉA, there is no gold annotation but only the unmerged annotations from two annotators. As in Bögel et al. (2014), we only use those tokens for accuracy calculation which had been annotated with the same tense from both annotators, and we combine future imperfect and future perfect into one tag.

\subsection{TMV and Modality Evaluation}

For the second evaluation, we used the annotations of finiteness, tense, mood, voice and modality for Don Quijote. Since Ramm et al. (2017)'s tagger only tags finite verb forms, we decided to only compare the performances of the taggers on clauses annotated as finite. We further combined indicative and imperative mood as well as static passive and dynamic passive to have the same categories as Ramm et al. (2017). The first column of Table 3 shows the performance of Ramm et al. (2017)'s and our tagger for detecting whether a verb form is finite or non-finite. The other columns show the accuracies for correctly tagged main verbs in finite clauses. The last row shows the accuracies for our tagger when not merging mood and voice to Ramm et al. (2017)'s categories and evaluating on all verbs, including those in non-finite clauses.

\subsection{Clause Evaluation}

We also tested the sole performance of our clausizer. For the evaluation on Don Quijote, we compared the clause boundaries of the annotation $B_{\text {gold }}$ with the predicted boundaries $B_{\text {pred }}$ (cf. Jurish and Würzner (2013)). We define a clause boundary as a tuple $\left(e_{i}, s_{i+1}\right)$ of character positions, namely the end position $e_{i}$ of a clause and the start position $s_{i+1}$ of the next clause in the text. ${ }^{15}$ Precision, recall and $\mathrm{F}_{1}$-score are calculated respectively as

$$
P=\frac{\left|B_{\text {gold }} \cap B_{\text {pred }}\right|}{\left|B_{\text {pred }}\right|}, \quad R=\frac{\left|B_{\text {gold }} \cap B_{\text {pred }}\right|}{\left|B_{\text {gold }}\right|}, \quad \text { and } \quad F_{1}=\frac{2 \cdot P \cdot R}{P+R} .
$$

\footnotetext{
${ }^{15} \mathrm{~A}$ clause inside another clause produces the same boundaries as three subsequent clauses. It is not possible to distinguish these cases in the calculations, because the annotation format does not distinguish them either.
} 


\begin{tabular}{lccc}
\hline & $\begin{array}{c}\text { Don Quijote } \\
\text { clause boundaries }\end{array}$ & \multicolumn{2}{c}{ CoNLL-2001 } \\
clause starts & clause ends \\
\hline Gold instances & 443 & 4497 & 3364 \\
Pred. instances & 388 & 4598 & 4598 \\
Precision & 87.1 & 72.7 & 66.4 \\
Recall & 76.3 & 74.3 & 90.8 \\
$\mathrm{~F}_{1}$-score & 81.3 & 73.5 & 76.7 \\
\hline
\end{tabular}

Table 4: Clause splitting precisions, recalls and $\mathrm{F}_{1}$-scores of our clausizer on our test text (German) and the CoNLL-2001 shared task test set (English). The first two rows show the number of gold and predicted instances.

We additionally applied the clausizer to the test set from the CoNLL-2001 shared task on clause identification (in English) (Tjong Kim Sang and Déjean, 2001). The goal in the shared task was the automatic detection of 1) start tokens, 2) end tokens, and 3) entire spans of clauses. The evaluation of our tool on this dataset is somewhat problematic because the concept of what a clause is differs in several aspects. The main difference is that every token belongs to exactly one clause in our concept, namely the syntactically deepest clause where it appears in, whereas a token also belongs to all of its superordinate clauses in the shared task's concept. Therefore, our clausizer would definitely not detect the same spans as in the test set. However, we can evaluate the clausizer on the detection of clause starts and ends; here, the actual number of clauses that start or end on those positions is not considered. For the prediction, we used the sentence boundaries and part-of-speech tags as in the test set, the pre-trained English spaCy mode ${ }^{16}$ for parsing, and our clausizer in the same configuration as for German, with a small modification: As noted earlier, the English spaCy model does not use UD relations, but instead produces the earlier Stanford relations (de Marneffe and Manning, 2008) which are quite similar to the UD relations. We added csubjpass, intj, pcomp, and relcl (which do not appear in the UD inventory) to the list of clause-marking relations.

Table 4 shows the performances of the clausizer on Don Quijote and the English test set. We achieve $\mathrm{F}_{1}$-scores of $81.3 \%$ for clause boundaries in Don Quijote, and of $73.5 \%$ for clause starts and $76.7 \%$ for clause ends in the English test set, respectively. Note that the number of predicted starts is identical to the number of predicted ends, since every token is only part of one clause in our system. The number of gold starts and ends varies, since every token can be start and end of several (nested) clauses in the test set. The scores of the systems designed for and submitted to the shared task range between $50 \%$ and $92 \%$ for clause starts and $60 \%$ and $90 \%$ for clause ends, respectively.

\section{Discussion}

Our tagger achieves adequate accuracies for tense, mood and voice on the preface of Don Quijote, and outperforms the tagger from Ramm et al. (2017) in every evaluation condition, both on our test text as well as the heureCLÉA corpus. We perform about $4 \%$ worse on the heureCLÉA corpus than the original tagger of Bögel et al. (2014). A frequent cause for mismatches is the different treatment of nonfinite clauses, which frequently receive the tense of the matrix clause in the heureCLÉA corpus but are standardly tagged with present or perfect tense from our tagger. Clauses are not annotated with finiteness in heureCLÉA and it is therefore neither possible to exclude non-finite clauses from the evaluation, nor to estimate their exact impact. In Don Quijote, about $12 \%$ of the main verbs are annotated as non-finite, and one can assume that the amount in heureCLÉA is approximately the same.

A manual inspection of the tagger outputs shows that Ramm et al. (2017)'s tagger sometimes leaves entire clauses within complex sentences untagged which is probably an indication of incorrectly split clauses. Our clausizer, on the other hand, is more robust when it comes to these kinds of sentences. Ramm et al. (2017)'s tagger also tags verbs in past subjunctive, e.g. dächte 'would think', as present tense (which is usually the semantic tense) although its grammatical tense is the past tense. Again, our

\footnotetext{
${ }^{16}$ The pre-trained English model is available at https://spacy.io/models/en\#en_core_web_lg.
} 
complete look-up table is not as prone to errors as a set of rules.

Our comparatively low accuracy for mood mainly results from open clausal complements (xcomp in UD) that are not treated as clauses in our annotation but are recognised as such by the clausizer. Such clauses are non-finite and hence not tagged with mood. Mostly, these are cases where the annotators had overlooked an embedded infinitive clause, such as the underlined clause in (13), and then annotated it as part of the finite clause.

(13) i. (Gedichte,) die man den Büchern an den Eingang zu setzen pflegt

ii. (poems) that one uses to place at the beginning of the books

The tagging of modal verbs also leaves room for improvement. The main cause for this are conjuncted clauses in which the modal verb is not correctly copied from a main clause to its conjuncts by our conjunct handling algorithm.

Another type of error are incorrect analyses caused by preprocessing components. An example for this are perfect and pluperfect forms (e.g. hatte gesehen 'had seen') which are sometimes tagged as their respective imperfect tenses, present and preterite; e.g. because the morphological analyzer does not recognise the participle as such or the clausizer separates the verbs due to an incorrect parser output. Given parsing and clausizing performances of $85 \%$ and $81 \%$, it is encouraging that we reach TMV tagging accuracies of over $90 \%$. The influence of the syntactic preprocessing might be partially alleviated by the fact that our tagger itself does not use dependency information. Nevertheless, improvements in the parser would surely improve the performances of the clausizer and subsequently the tagger.

\section{Future Work}

As mentioned above, we oriented ourselves to usual German school grammars (Dudenredaktion, 2009) when building our tagsets for tense, mood and voice. However, it might be useful to also include non-canonical, but grammaticalised composite verb forms such as the already mentioned double perfect/pluperfect or the recipient passive (e.g. Ziering et al. (2012)) with the auxiliary verb bekommen 'receive'. To do so, nothing more is required than to extend the table of possible verb forms (the look-up function $R$ ).

Our approach works for every language with a hierarchically ordered verb structure, such as German and English. To adapt our approach to another language, a morphological analyzer of that language, a table of verb forms and perhaps a list of modal verbs is required. Resources such as Wiktionary provide verb type information and inflection tables for numerous languages and can be used with little effort. Our clausizer, which relies on Universal Dependencies relations, already works language-independently.

Future work could also address the transition from rule-based systems to distributional models. Although mapping morphological features to clausal features is a strictly rule-based process, grouping verbs into verb forms and selecting context-specific analyses for all relevant verbs is not. Since training these models usually requires a certain amount of annotated data, a preliminary step would be the creation of sufficient corpora. For example, clause-level features could be added to the Universal Dependencies treebanks, as they already have the concept of clause-marking dependency relations.

\section{Conclusion}

In this work, we provide a rule-based method to detect grammatical/morphosyntactic tense, mood, voice and modality on clause level in German. Our algorithm is grounded in linguistic theory and makes use of the hierarchically ordered verb structure in German. We also provide our preprocessing pipeline (implemented in Python/spaCy), including a German parsing model for Universal Dependencies (UD), a language-independent clausizer that splits sentences with UD parses into clauses, and an interface to the morphological analyzer DEMoprhy. We evaluated our approach on literary texts and achieve new state-of-the-art accuracies in all categories. Since our algorithm is rule-based, it does not require any training data and can be used for other text domains as well. 


\section{Acknowledgements}

My thanks go to Caroline Sporleder, Luisa Gödeke and Franziska Pannach, who advised me on the development of this work. I further thank the three anonymous reviewers for their valuable comments and their suggestions for how to improve this paper. This work was supported by the VolkswagenStiftung within the initiative "Geistes- und Kulturwissenschaften - digital: Forschungschancen, Methodenentwicklung und Reflexionspotenziale".

\section{References}

Duygu Altinok. 2018. DEMorphy, German language morphological analyzer. arXiv:1803.00902.

Andreas Ammann. 2007. The fate of 'redundant' verbal forms - double perfect constructions in the languages of Europe. STUF - Language Typology and Universals, 60(3):186-204.

Howard I. Aronson. 1995. Towards a typology of verbal categories. In New vistas in grammar: Invariance and variation, pages 111-131. John Benjamins Publishing.

Karin Bausewein. 1991. AcI-Konstruktionen und Valenz. In Eberhard Klein, Françoise Pouradier Duteil, and Karl Heinz Wagner, editors, Betriebslinguistik und Linguistikbetrieb, number 260 in Linguistische Arbeiten, pages 245-251. Tübingen: Niemeyer.

Thomas Bögel, Jannik Strötgen, and Michael Gertz. 2014. Computational narratology: Extracting tense clusters from narrative texts. In Proceedings of the Ninth International Conference on Language Resources and Evaluation (LREC'14), pages 950-955, Reykjavik, Iceland, May. European Language Resources Association (ELRA).

Ronny Boogaart and Theo Janssen. 2007. Tense and aspect. In The Oxford handbook of cognitive linguistics.

Sabine Buchholz and Erwin Marsi. 2006. CoNLL-X shared task on multilingual dependency parsing. In Proceedings of the Tenth Conference on Computational Natural Language Learning (CoNLL-X), pages 149-164, New York City, June. Association for Computational Linguistics.

Marie-Catherine de Marneffe and Christopher D. Manning. 2008. Stanford typed dependencies manual. Technical report, Stanford University.

Dudenredaktion, editor. 2009. Die Grammatik. Unentbehrlich für richtiges Deutsch. Number 4 in Duden. Dudenverlag, $8^{\text {th }}$ edition.

Jennifer R. Elliott. 2000. Realis and irrealis: Forms and concepts of the grammaticalisation of reality. Linguistic Typology, 4(1):55-90.

Joseph L. Fleiss, Bruce Levin, and Myunghee Cho Paik, 2003. The measurement of interrater agreement, chapter 18. John Wiley \& Sons, $3^{\text {rd }}$ edition.

Jan Hajič, Massimiliano Ciaramita, Richard Johansson, Daisuke Kawahara, Maria Antònia Martí, Lluís Màrquez, Adam Meyers, Joakim Nivre, Sebastian Padó, Jan Štěpánek, Pavel Straňák, Mihai Surdeanu, Nianwen Xue, and Yi Zhang. 2009. The CoNLL-2009 shared task: Syntactic and semantic dependencies in multiple languages. In Proceedings of the Thirteenth Conference on Computational Natural Language Learning (CoNLL 2009): Shared Task, pages 1-18, Boulder, Colorado, June. Association for Computational Linguistics.

Erhard Hinrichs. 2016. Substitute infinitives and Oberfeld placement of auxiliaries in German subordinate clauses: A synchronic and diachronic corpus study using the CLARIN research infrastructure. Lingua, 178:46-70. Linguistic Research in the CLARIN Infrastructure.

Daniel Jurafsky and James H. Martin. 2009. Features and unification. In Speech and Language Processing, chapter 15 . Pearson, $2^{\text {nd }}$ edition.

Bryan Jurish and Kay-Michael Würzner. 2013. Word and sentence tokenization with hidden Markov models. Journal for Language Technology and Computational Linguistics, 28(2):61-83.

Edward L. Keenan and Matthew S. Dryer, 2007. Passive in the world's languages, volume 1, pages 325-361. Cambridge University Press, $2^{\text {nd }}$ edition. 
Philipp Koehn. 2005. Europarl: A parallel corpus for statistical machine translation. In Conference Proceedings: The Tenth Machine Translation Summit, Phuket, Thailand.

Elisabeth Leiss. 2008. The silent and aspect-driven patterns of deonticity and epistemicity. Modality-aspect interfaces: Implications and typological solutions, pages 15-41.

Jo-Wang Lin. 2005. Time in a Language Without Tense: The Case of Chinese. Journal of Semantics, 23(1):1-53, 09.

Joakim Nivre, Marie-Catherine de Marneffe, Filip Ginter, Yoav Goldberg, Jan Hajič, Christopher D. Manning, Ryan McDonald, Slav Petrov, Sampo Pyysalo, Natalia Silveira, Reut Tsarfaty, and Daniel Zeman. 2016. Universal Dependencies v1: A multilingual treebank collection. In Proceedings of the Tenth International Conference on Language Resources and Evaluation (LREC'16), pages 1659-1666, Portorož, Slovenia, May. European Language Resources Association (ELRA).

James Pustejovsky and Marc Verhagen. 2009. SemEval-2010 task 13: Evaluating events, time expressions, and temporal relations (TempEval-2). In Proceedings of the Workshop on Semantic Evaluations: Recent Achievements and Future Directions (SEW-2009), pages 112-116, Boulder, Colorado, June. Association for Computational Linguistics.

Anita Ramm, Sharid Loáiciga, Annemarie Friedrich, and Alexander Fraser. 2017. Annotating tense, mood and voice for English, French and German. In Proceedings of ACL 2017, System Demonstrations, pages 1-6, Vancouver, Canada, July. Association for Computational Linguistics.

Hans Reichenbach. 1947. Elements of symbolic logic.

Helmut Schmid. 1995. Improvements in part-of-speech tagging with an application to German. In Proceedings of the ACL SIGDAT-Workshop, Dublin, Ireland.

Anil Kumar Singh, Samar Husain, Harshit Surana, Jagadeesh Gorla, Dipti Misra Sharma, and Chinnappa Guggilla. 2007. Disambiguating tense, aspect and modality markers for correcting machine translation errors. In Proceedings of the Conference on Recent Advances in Natural Language Processing (RANLP).

Jannik Strötgen and Michael Gertz. 2010. Heideltime: High quality rule-based extraction and normalization of temporal expressions. In Proceedings of the 5th International Workshop on Semantic Evaluation, pages 321324.

Kalevi Tarvainen. 1976. Die Modalverben im Deutschen Modus- und Tempussystem. Neuphilologische Mitteilungen, 77(1):9-24.

Erik F. Tjong Kim Sang and Hervé Déjean. 2001. Introduction to the CoNLL-2001 shared task: clause identification. In Proceedings of the ACL 2001 Workshop on Computational Natural Language Learning (ConLL).

Emanuel Viebahn and Barbara Vetter. 2016. How many meanings for 'may'? The case for modal polysemy. Philosopher's Imprint, 16(10).

Nessa Wolfson. 1978. A feature of performed narrative: The conversational historical present. Language in Society, 7(2):215-237.

Elizabeth Zeitoun, Lillian M. Huang, Marie M. Yeh, Anna H. Chang, and Joy J. Wu. 1996. The temporal, aspectual, and modal systems of some formosan languages: A typological perspective. Oceanic Linguistics, $35(1): 21-56$.

Daniel Zeman, Martin Popel, Milan Straka, Jan Hajič, Joakim Nivre, Filip Ginter, Juhani Luotolahti, Sampo Pyysalo, Slav Petrov, Martin Potthast, Francis Tyers, Elena Badmaeva, Memduh Gokirmak, Anna Nedoluzhko, Silvie Cinková, Jan Hajič jr., Jaroslava Hlaváčová, Václava Kettnerová, Zdeňka Urešová, Jenna Kanerva, Stina Ojala, Anna Missilä, Christopher D. Manning, Sebastian Schuster, Siva Reddy, Dima Taji, Nizar Habash, Herman Leung, Marie-Catherine de Marneffe, Manuela Sanguinetti, Maria Simi, Hiroshi Kanayama, Valeria de Paiva, Kira Droganova, Héctor Martínez Alonso, Çağrı Çöltekin, Umut Sulubacak, Hans Uszkoreit, Vivien Macketanz, Aljoscha Burchardt, Kim Harris, Katrin Marheinecke, Georg Rehm, Tolga Kayadelen, Mohammed Attia, Ali Elkahky, Zhuoran Yu, Emily Pitler, Saran Lertpradit, Michael Mandl, Jesse Kirchner, Hector Fernandez Alcalde, Jana Strnadová, Esha Banerjee, Ruli Manurung, Antonio Stella, Atsuko Shimada, Sookyoung Kwak, Gustavo Mendonça, Tatiana Lando, Rattima Nitisaroj, and Josie Li. 2017. CoNLL 2017 shared task: Multilingual parsing from raw text to Universal Dependencies. In Proceedings of the CoNLL 2017 Shared Task: Multilingual Parsing from Raw Text to Universal Dependencies, pages 1-19, Vancouver, Canada, August. Association for Computational Linguistics. 
Daniel Zeman, Joakim Nivre, Mitchell Abrams, Elia Ackermann, Noëmi Aepli, Željko Agić, Lars Ahrenberg, Chika Kennedy Ajede, Gabrielè Aleksandravičiūtė, Lene Antonsen, Katya Aplonova, Angelina Aquino, Maria Jesus Aranzabe, Gashaw Arutie, Masayuki Asahara, Luma Ateyah, Furkan Atmaca, Mohammed Attia, Aitziber Atutxa, Liesbeth Augustinus, Elena Badmaeva, Miguel Ballesteros, Esha Banerjee, Sebastian Bank, Verginica Barbu Mititelu, Victoria Basmov, Colin Batchelor, John Bauer, Kepa Bengoetxea, Yevgeni Berzak, Irshad Ahmad Bhat, Riyaz Ahmad Bhat, Erica Biagetti, Eckhard Bick, Agnė Bielinskienė, Rogier Blokland, Victoria Bobicev, Loïc Boizou, Emanuel Borges Völker, Carl Börstell, Cristina Bosco, Gosse Bouma, Sam Bowman, Adriane Boyd, Kristina Brokaite, Aljoscha Burchardt, Marie Candito, Bernard Caron, Gauthier Caron, Tatiana Cavalcanti, Gülşen Cebiroğlu Eryiğit, Flavio Massimiliano Cecchini, Giuseppe G. A. Celano, Slavomír Čéplö, Savas Cetin, Fabricio Chalub, Ethan Chi, Jinho Choi, Yongseok Cho, Jayeol Chun, Alessandra T. Cignarella, Silvie Cinková, Aurélie Collomb, Çağrı Çöltekin, Miriam Connor, Marine Courtin, Elizabeth Davidson, Marie-Catherine de Marneffe, Valeria de Paiva, Elvis de Souza, Arantza Diaz de Ilarraza, Carly Dickerson, Bamba Dione, Peter Dirix, Kaja Dobrovoljc, Timothy Dozat, Kira Droganova, Puneet Dwivedi, Hanne Eckhoff, Marhaba Eli, Ali Elkahky, Binyam Ephrem, Olga Erina, Tomaž Erjavec, Aline Etienne, Wograine Evelyn, Richárd Farkas, Hector Fernandez Alcalde, Jennifer Foster, Cláudia Freitas, Kazunori Fujita, Katarína Gajdošová, Daniel Galbraith, Marcos Garcia, Moa Gärdenfors, Sebastian Garza, Kim Gerdes, Filip Ginter, Iakes Goenaga, Koldo Gojenola, Memduh Gökırmak, Yoav Goldberg, Xavier Gómez Guinovart, Berta González Saavedra, Bernadeta Griciūtè, Matias Grioni, Loïc Grobol, Normunds Grūzītis, Bruno Guillaume, Céline Guillot-Barbance, Tunga Güngör, Nizar Habash, Jan Hajič, Jan Hajič jr., Mika Hämäläinen, Linh Hà Mỹ, Na-Rae Han, Kim Harris, Dag Haug, Johannes Heinecke, Oliver Hellwig, Felix Hennig, Barbora Hladká, Jaroslava Hlaváčová, Florinel Hociung, Petter Hohle, Jena Hwang, Takumi Ikeda, Radu Ion, Elena Irimia, Olájídé Ishola, Tomáš Jelínek, Anders Johannsen, Hildur Jónsdóttir, Fredrik Jørgensen, Markus Juutinen, Hüner Kaşıkara, Andre Kaasen, Nadezhda Kabaeva, Sylvain Kahane, Hiroshi Kanayama, Jenna Kanerva, Boris Katz, Tolga Kayadelen, Jessica Kenney, Václava Kettnerová, Jesse Kirchner, Elena Klementieva, Arne Köhn, Abdullatif Köksal, Kamil Kopacewicz, Timo Korkiakangas, Natalia Kotsyba, Jolanta Kovalevskaitė, Simon Krek, Sookyoung Kwak, Veronika Laippala, Lorenzo Lambertino, Lucia Lam, Tatiana Lando, Septina Dian Larasati, Alexei Lavrentiev, John Lee, Phuong Lê Hồng, Alessandro Lenci, Saran Lertpradit, Herman Leung, Maria Levina, Cheuk Ying Li, Josie Li, Keying Li, KyungTae Lim, Yuan Li, Nikola Ljubešić, Olga Loginova, Olga Lyashevskaya, Teresa Lynn, Vivien Macketanz, Aibek Makazhanov, Michael Mandl, Christopher Manning, Ruli Manurung, Cătălina Mărănduc, David Mareček, Katrin Marheinecke, Héctor Martínez Alonso, André Martins, Jan Mašek, Hiroshi Matsuda, Yuji Matsumoto, Ryan McDonald, Sarah McGuinness, Gustavo Mendonça, Niko Miekka, Margarita Misirpashayeva, Anna Missilä, Cătălin Mititelu, Maria Mitrofan, Yusuke Miyao, Simonetta Montemagni, Amir More, Laura Moreno Romero, Keiko Sophie Mori, Tomohiko Morioka, Shinsuke Mori, Shigeki Moro, Bjartur Mortensen, Bohdan Moskalevskyi, Kadri Muischnek, Robert Munro, Yugo Murawaki, Kaili Müürisep, Pinkey Nainwani, Juan Ignacio Navarro Horñiacek, Anna Nedoluzhko, Gunta Nešpore-Bērzkalne, Luong Nguyễn Thị, Huyền Nguyễn Thị Minh, Yoshihiro Nikaido, Vitaly Nikolaev, Rattima Nitisaroj, Hanna Nurmi, Stina Ojala, Atul Kr. Ojha, Adédayọ Olúòkun, Mai Omura, Emeka Onwuegbuzia, Petya Osenova, Robert Östling, Lilja Øvrelid, Şaziye Betül Özateş, Arzucan Özgür, Balkız Öztürk Başaran, Niko Partanen, Elena Pascual, Marco Passarotti, Agnieszka Patejuk, Guilherme Paulino-Passos, Angelika Peljak-Łapińska, Siyao Peng, Cenel-Augusto Perez, Guy Perrier, Daria Petrova, Slav Petrov, Jason Phelan, Jussi Piitulainen, Tommi A Pirinen, Emily Pitler, Barbara Plank, Thierry Poibeau, Larisa Ponomareva, Martin Popel, Lauma Pretkalnina, Sophie Prévost, Prokopis Prokopidis, Adam Przepiórkowski, Tiina Puolakainen, Sampo Pyysalo, Peng Qi, Andriela Rääbis, Alexandre Rademaker, Loganathan Ramasamy, Taraka Rama, Carlos Ramisch, Vinit Ravishankar, Livy Real, Petru Rebeja, Siva Reddy, Georg Rehm, Ivan Riabov, Michael Rießler, Erika Rimkute, Larissa Rinaldi, Laura Rituma, Luisa Rocha, Mykhailo Romanenko, Rudolf Rosa, Valentin Roșca, Davide Rovati, Olga Rudina, Jack Rueter, Shoval Sadde, Benoît Sagot, Shadi Saleh, Alessio Salomoni, Tanja Samardžić, Stephanie Samson, Manuela Sanguinetti, Dage Särg, Baiba Saulīte, Yanin Sawanakunanon, Salvatore Scarlata, Nathan Schneider, Sebastian Schuster, Djamé Seddah, Wolfgang Seeker, Mojgan Seraji, Mo Shen, Atsuko Shimada, Hiroyuki Shirasu, Muh Shohibussirri, Dmitry Sichinava, Aline Silveira, Natalia Silveira, Maria Simi, Radu Simionescu, Katalin Simkó, Mária Šimková, Kiril Simov, Maria Skachedubova, Aaron Smith, Isabela Soares-Bastos, Carolyn Spadine, Antonio Stella, Milan Straka, Jana Strnadová, Alane Suhr, Umut Sulubacak, Shingo Suzuki, Zsolt Szántó, Dima Taji, Yuta Takahashi, Fabio Tamburini, Takaaki Tanaka, Samson Tella, Isabelle Tellier, Guillaume Thomas, Liisi Torga, Marsida Toska, Trond Trosterud, Anna Trukhina, Reut Tsarfaty, Utku Türk, Francis Tyers, Sumire Uematsu, Roman Untilov, Zdeňka Urešová, Larraitz Uria, Hans Uszkoreit, Andrius Utka, Sowmya Vajjala, Daniel van Niekerk, Gertjan van Noord, Viktor Varga, Eric Villemonte de la Clergerie, Veronika Vincze, Aya Wakasa, Lars Wallin, Abigail Walsh, Jing Xian Wang, Jonathan North Washington, Maximilan Wendt, Paul Widmer, Seyi Williams, Mats Wirén, Christian Wittern, Tsegay Woldemariam, Tak-sum Wong, Alina Wróblewska, Mary Yako, Kayo Yamashita, Naoki Yamazaki, Chunxiao Yan, Koichi Yasuoka, Marat M. Yavrumyan, Zhuoran Yu, Zdeněk Žabokrtský, Amir Zeldes, Hanzhi Zhu, and Anna Zhuravleva. 2020. Universal Dependencies 2.6. LINDAT/CLARIAH-CZ digital library at the Institute of Formal and Applied Linguistics (ÚFAL), Faculty of Mathematics and Physics, Charles University. 
for German. In Cerstin Mahlow and Michael Piotrowski, editors, State of the Art in Computational Morphology, pages 64-75, Berlin, Heidelberg. Springer Berlin Heidelberg.

Patrick Ziering, Sina Zarrieß, and Jonas Kuhn. 2012. A corpus-based study of the German recipient passive. In Proceedings of the Eighth International Conference on Language Resources and Evaluation (LREC'12), pages 1637-1644, Istanbul, Turkey, May. European Language Resources Association (ELRA).

Appendix A. German verb forms with tense, mood, voice

\begin{tabular}{|c|c|c|c|c|}
\hline Aux. & Example & Tense + Aspect & Mood (if finite) & Voice \\
\hline haben & (zu) sehen & present imperfect & (infinitive) & active \\
\hline haben & gesehen $(\mathrm{zu})$ werden & present imperfect & (infinitive) & dynamic passive \\
\hline haben & gesehen $(\mathrm{zu})$ sein & present imperfect & (infinitive) & static passive \\
\hline haben & gesehen (zu) haben & present perfect & (infinitive) & active \\
\hline haben & gesehen worden (zu) sein & present perfect & (infinitive) & dynamic passive \\
\hline haben & gesehen gewesen $(\mathrm{zu})$ sein & present perfect & (infinitive) & static passive \\
\hline haben & sehend & present imperfect & (participle) & active \\
\hline haben & gesehen & present perfect & (participle) & passive \\
\hline haben & sieh & present imperfect & imperative & active \\
\hline haben & werde gesehen & present imperfect & imperative & dynamic passive \\
\hline haben & sei gesehen & present imperfect & imperative & static passive \\
\hline haben & habe gesehen & present perfect & imperative & active \\
\hline haben & sei gesehen worden & present perfect & imperative & dynamic passive \\
\hline haben & sei gesehen gewesen & present perfect & imperative & static passive \\
\hline haben & [er] sieht & present imperfect & indicative & active \\
\hline haben & [er] sehe & present imperfect & present subjunctive & active \\
\hline haben & [er] wird gesehen & present imperfect & indicative & dynamic passive \\
\hline haben & [er] werde gesehen & present imperfect & present subjunctive & dynamic passive \\
\hline haben & [er] ist gesehen & present imperfect & indicative & static passive \\
\hline haben & [er] sei gesehen & present imperfect & present subjunctive & static passive \\
\hline haben & [er] sah & past imperfect & indicative & active \\
\hline haben & [er] sähe & past imperfect & past subjunctive & active \\
\hline haben & [er] wurde gesehen & past imperfect & indicative & dynamic passive \\
\hline haben & [er] würde gesehen & past imperfect & past subjunctive & dynamic passive \\
\hline haben & [er] war gesehen & past imperfect & indicative & static passive \\
\hline haben & [er] wäre gesehen & past imperfect & past subjunctive & static passive \\
\hline haben & [er] hat gesehen & present perfect & indicative & active \\
\hline haben & [er] habe gesehen & present perfect & present subjunctive & active \\
\hline haben & [er] ist gesehen worden & present perfect & indicative & dynamic passive \\
\hline haben & [er] sei gesehen worden & present perfect & present subjunctive & dynamic passive \\
\hline haben & [er] ist gesehen gewesen & present perfect & indicative & static passive \\
\hline haben & [er] sei gesehen gewesen & present perfect & present subjunctive & static passive \\
\hline haben & [er] hatte gesehen & past perfect & indicative & active \\
\hline haben & [er] hätte gesehen & past perfect & past subjunctive & active \\
\hline haben & [er] war gesehen worden & past perfect & indicative & dynamic passive \\
\hline haben & [er] wäre gesehen worden & past perfect & past subjunctive & dynamic passive \\
\hline haben & [er] war gesehen gewesen & past perfect & indicative & static passive \\
\hline haben & [er] wäre gesehen gewesen & past perfect & past subjunctive & static passive \\
\hline haben & [er] wird sehen & future imperfect & indicative & active \\
\hline haben & [er] werde sehen & future imperfect & present subjunctive & active \\
\hline
\end{tabular}




\begin{tabular}{|c|c|c|c|c|}
\hline Aux. & Example & Tense + Aspect & Mood (if finite) & Voice \\
\hline haben & [er] würde sehen & future imperfect & past subjunctive & active \\
\hline haben & [er] wird gesehen werden & future imperfect & indicative & dynamic passive \\
\hline haben & [er] werde gesehen werden & future imperfect & present subjunctive & dynamic passive \\
\hline haben & [er] würde gesehen werden & future imperfect & past subjunctive & dynamic passive \\
\hline haben & [er] wird gesehen sein & future imperfect & indicative & static passive \\
\hline haben & [er] werde gesehen sein & future imperfect & present subjunctive & static passive \\
\hline haben & [er] würde gesehen sein & future imperfect & past subjunctive & static passive \\
\hline haben & [er] wird gesehen haben & future perfect & indicative & active \\
\hline haben & [er] werde gesehen haben & future perfect & present subjunctive & active \\
\hline haben & [er] würde gesehen haben & future perfect & past subjunctive & active \\
\hline haben & [er] wird gesehen worden sein & future perfect & indicative & dynamic passive \\
\hline haben & [er] werde gesehen worden sein & future perfect & present subjunctive & dynamic passive \\
\hline haben & [er] würde gesehen worden sein & future perfect & past subjunctive & dynamic passive \\
\hline haben & [er] wird gesehen gewesen sein & future perfect & indicative & static passive \\
\hline haben & [er] werde gesehen gewesen sein & future perfect & present subjunctive & static passive \\
\hline haben & [er] würde gesehen gewesen sein & future perfect & past subjunctive & static passive \\
\hline sein & (zu) gehen & present imperfect & infinitive & active \\
\hline sein & gegangen $(\mathrm{zu})$ werden & present imperfect & infinitive & dynamic passive \\
\hline sein & gegangen (zu) sein & present imperfect & infinitive & static passive \\
\hline sein & gegangen $(\mathrm{zu})$ sein & present perfect & infinitive & active \\
\hline sein & gegangen worden $(\mathrm{zu})$ sein & present perfect & infinitive & dynamic passive \\
\hline sein & gegangen gewesen $(\mathrm{zu})$ sein & present perfect & infinitive & static passive \\
\hline sein & gehend & present imperfect & participle & active \\
\hline sein & gegangen & present perfect & participle & pass \\
\hline sein & geh & present imperfect & imperative & active \\
\hline sein & werde gegangen & present imperfect & imperative & dynamic passive \\
\hline sein & sei gegangen & present imperfect & imperative & static passive \\
\hline sein & sei gegangen & present perfect & imperative & active \\
\hline sein & sei gegangen worden & present perfect & imperative & dynamic passive \\
\hline sein & sei gegangen gewesen & present perfect & imperative & static passive \\
\hline sein & [er] geht & present imperfect & indicative & active \\
\hline sein & [er] gehe & present imperfect & present subjunctive & active \\
\hline sein & [er] wird gegangen & present imperfect & indicative & dynamic passive \\
\hline sein & [er] werde gegangen & present imperfect & present subjunctive & dynamic passive \\
\hline sein & [er] ist gegangen & present imperfect & indicative & static passive \\
\hline sein & [er] sei gegangen & present imperfect & present subjunctive & static passive \\
\hline sein & [er] ging & past imperfect & indicative & active \\
\hline sein & [er] ginge & past imperfect & past subjunctive & active \\
\hline sein & [er] wurde gegangen & past imperfect & indicative & dynamic passive \\
\hline sein & [er] würde gegangen & past imperfect & past subjunctive & dynamic passive \\
\hline sein & [er] war gegangen & past imperfect & indicative & static passive \\
\hline sein & [er] wäre gegangen & past imperfect & past subjunctive & static passive \\
\hline sein & [er] ist gegangen & present perfect & indicative & active \\
\hline sein & [er] sei gegangen & present perfect & present subjunctive & active \\
\hline sein & [er] ist gegangen worden & present perfect & indicative & dynamic passive \\
\hline sein & [er] sei gegangen worden & present perfect & present subjunctive & dynamic passive \\
\hline
\end{tabular}




\begin{tabular}{|c|c|c|c|c|}
\hline Aux. & Example & Tense + Aspect & Mood (if finite) & Voice \\
\hline sein & [er] ist gegangen gewesen & present perfect & indicative & static passive \\
\hline sein & [er] sei gegangen gewesen & present perfect & present subjunctive & static passive \\
\hline sein & [er] war gegangen & past perfect & indicative & active \\
\hline sein & [er] wäre gegangen & past perfect & past subjunctive & active \\
\hline sein & [er] war gegangen worden & past perfect & indicative & dynamic passive \\
\hline sein & [er] wäre gegangen worden & past perfect & past subjunctive & dynamic passive \\
\hline sein & [er] war gegangen gewesen & past perfect & indicative & static passive \\
\hline sein & [er] wäre gegangen gewesen & past perfect & past subjunctive & static passive \\
\hline sein & [er] wird gehen & future imperfect & indicative & active \\
\hline sein & [er] werde gehen & future imperfect & present subjunctive & active \\
\hline sein & [er] würde gehen & future imperfect & past subjunctive & active \\
\hline sein & [er] wird gegangen werden & future imperfect & indicative & dynamic passive \\
\hline sein & [er] werde gegangen werden & future imperfect & present subjunctive & dynamic passive \\
\hline sein & [er] würde gegangen werden & future imperfect & past subjunctive & dynamic passive \\
\hline sein & [er] wird gegangen sein & future imperfect & indicative & static passive \\
\hline sein & [er] werde gegangen sein & future imperfect & present subjunctive & static passive \\
\hline sein & [er] würde gegangen sein & future imperfect & past subjunctive & static passive \\
\hline sein & [er] wird gegangen sein & future perfect & indicative & active \\
\hline sein & [er] werde gegangen sein & future perfect & present subjunctive & active \\
\hline sein & [er] würde gegangen sein & future perfect & past subjunctive & active \\
\hline sein & [er] wird gegangen worden sein & future perfect & indicative & dynamic passive \\
\hline sein & [er] werde gegangen worden sein & future perfect & present subjunctive & dynamic passive \\
\hline sein & [er] würde gegangen worden sein & future perfect & past subjunctive & dynamic passive \\
\hline sein & [er] wird gegangen gewesen sein & future perfect & indicative & static passive \\
\hline sein & [er] werde gegangen gewesen sein & future perfect & present subjunctive & static passive \\
\hline sein & [er] würde gegangen gewesen sein & future perfect & past subjunctive & static passive \\
\hline
\end{tabular}

Table 5: Composite verb forms in German. The first column shows the auxiliary verb used for the perfect aspect. An example for a verb using haben 'have' is sehen 'see'; an example for a verb using sein 'be' is gehen 'go'. 